\title{
PENGGUNAAN METODE SMOOTHING EKSPONENSIAL DALAM MERAMAL PERGERAKAN INFLASI KOTA PALU
}

\author{
Romy Biri $^{1)}$, Yohanes A.R. Langi ${ }^{1)}$, Marline S. Paendong ${ }^{1)}$ \\ ${ }^{1)}$ Program Studi Matematika FMIPA Universitas Sam Ratulangi \\ Jl. Kampus Unsrat, Manado 95115 \\ e-mail : romybiri@yahoo.com ; yarlangi@gmail.com ; marline_paendong@yahoo.com
}

\begin{abstract}
ABSTRAK
Penelitian dilakukan untuk mengetahui pergerakan inflasi dan meramal pergerakan inflasi di Kota Palu. Data pergerakan inflasi ini berjumlah 160 data bulan pengamatan, dari januari 2000 sampai april 2013. Peramalan pergerakan inflasi di Kota Palu sebesar 0,2683 persen, artinya pergerakan inflasi di Kota Palu kembali mengalami penurunan dari periode bulan sebelumnya. Data peramalan pergerakan ini, tidak mengalami perbedaan yang signifikan di bandingkan dengan data yang di keluarkan oleh Badan Pusat Statistika di kota tersebut.
\end{abstract}

Kata kunci : Meramal Pergerakan Inflasi, Smoothing Eksponential tunggal

\section{THE USING OF EXPONENTIAL SMOOTHING METHOD TO PREDICT INFLATION MOVEMENT FROM PALU CITY}

\begin{abstract}
The Research was conducted to determine the movement of inflation and predicting it in Palu. The data of inflation movement numbered 160 data observation month, from January 2000 until April 2013. Predicting the movement of inflation in Palu of 0,2683 percent, it means the movement of inflation in Palu decreased again from month period previously. The data of these movement, not significant difference in comporison with the data that released by Central Statistical Corporation in the city.
\end{abstract}

Keywords : Predicting the Movement of Inflation, Single Exponential Smoothing

\section{PENDAHULUAN}

Secara sederhana inflasi diartikan sebagai meningkatnya harga-harga secara umum dan terus menerus. Kenaikan harga dari satu atau dua barang saja tidak dapat disebut inflasi kecuali bila kenaikan itu meluas (atau mengakibatkan kenaikan harga) pada barang lainnya. Kebalikan dari inflasi disebut deflasi. (Sumber: Bank Indonesia)

Indikator yang sering digunakan untuk mengukur tingkat inflasi adalah Indeks Harga Konsumen (IHK). Perubahan IHK dari waktu ke waktu menunjukkan pergerakan harga dari paket barang dan jasa yang dikonsumsi masyarakat. Sejak Juli 2008, paket barang dan jasa dalam keranjang IHK telah dilakukan atas dasar Survei Biaya Hidup (SBH) Tahun 2007 yang dilaksanakan oleh Badan Pusat Statistik (BPS). Kemudian, BPS akan memonitor perkembangan harga dari barang dan jasa tersebut secara bulanan di beberapa kota, di pasar tradisional dan modern terhadap beberapa jenis barang/jasa di setiap kota.

Untuk mewujudkan pertumbuhan ekonomi yang berkesinambungan, maka pemerintah wajib melakukan salah satu syaratnya yaitu kestabilan inflasi. Kestabilan ini diharapkan nantinya dapat memberikan manfaat bagi peningkatan kesejahteraan masyarakat. Pentingnya pengendalian inflasi didasarkan pada pertimbangan bahwa inflasi yang tinggi dan tidak stabil memberikan dampak negatif kepada kondisi sosial ekonomi masyarakat. Inflasi yang tinggi akan menyebabkan pendapatan masyarakat akan terus menurun, sehingga standar hidup dari masyarakat pun turun dan akhirnya akan menjadikan semua orang, terutama orangorang miskin, bertambah miskin. Selain hal tersebut, keadaan inflasi yang tidak stabil akan menciptakan ketidakpastian bagi pelaku ekonomi dalam mengambil keputusan. Dari pengalaman yang sudah-sudah menunjukkan 
bahwa inflasi yang tidak stabil akan menyulitkan keputusan masyarakat dalam melakukan konsumsi, investasi, maupun produksi, yang pada akhirnya akan menurunkan pertumbuhan ekonomi nasional.

\section{TINJAUAN PUSTAKA}

\section{Inflasi}

Menurut Rahardja (1997) inflasi adalah kecenderungan dari harga-harga untuk meningkat secara umum dan terus-menerus. Kenaikan harga dari satu atau dua barang saja tidak disebut inflasi, tetapi jika kenaikan meluas kepada sebagian besar harga barangbarang maka hal ini disebut inflasi.

\section{Peramalan dengan Metode Rata-rata Bergerak (Moving Average)}

Rata-rata bergerak (moving averages) diperoleh melalui penjumlahan dan pencarian nilai rata-rata dari sejumlah periode tertentu, setiap kali meghilangkan nilai terlama dan menambah nilai baru (Subagyo, 1986).

\section{Rata-rata Bergerak Orde Satu (Single Moving Average) \\ Cara membuat peramalan} (forecasting) dengan metode Rata-rata bergerak orde satu (single moving averages) sangat sederhana, dengan rumus sebagai berikut:

$S_{T+1}=\frac{X_{1}+X_{2}+\cdots+X_{T}}{T}=\frac{1}{T} \sum_{i=1}^{T} X_{i} \ldots(1)$

$S_{T+2}=\frac{X_{2}+\cdots+X_{T}+X_{T+1}}{T}=\frac{1}{T} \sum_{i=2}^{T+1} X_{i}(2)$

(Subagyo, 1986)

dengan :

$\mathrm{S}_{\mathrm{T}+1}=$ forecast untuk periode ke $\mathrm{T}+1$

$\mathrm{X}_{\mathrm{T}}=$ data pada periode $\mathrm{T}$

$\mathrm{T}=$ jangka waktu rata-rata bergerak (moving average)

$\mathrm{S}_{\mathrm{T}+2}=$ forecast untuk periode $\mathrm{ke} \mathrm{T}+2$

\section{Rata-rata Bergerak Orde Dua (Double Moving Average)}

Metode ini digunakan untuk data yang mengandung trend linier. Peramalan dilakukan melalui beberapa tahap berikut:
i. $\quad M_{t}=S_{t+1}=\frac{X_{t+X_{t-1}+\ldots+X_{t-n+1}}}{n}$
ii. $M_{t}^{\prime}=\frac{\left(M_{t}+M_{t+1}+\ldots+M_{t-n+1}\right)}{n}$
iii. $a_{t}=2 M_{t}-M_{t}^{\prime}$

iv. $b_{t}=\frac{2}{n-1}\left(M_{t}-M_{t}^{\prime}\right)$

Peramalan dilakukan menggunakan model berikut ini:

$\hat{Y}_{t-P}=a_{t}+b_{t} p$

Peramalan (forecasting) dengan metode Penghalusan Eksponensial (Exponential Smoothing)

Penghalusan

eksponensial (exponential smoothing) adalah suatu tipe teknik peramalan rata-rata bergerak yang melakukan penimbangan terhadap data masa lalu dengan cara eksponensial sehingga data paling akhir mempunyai bobot atau timbangan lebih besar dalam rata-rata bergerak. (Handoko, 1984).

\section{Metode Penghalusan Eksponensial Orde Satu (Single Exponential Smoothing)}

Metode penghalusan eksponensial orde satu (single exponential smoothing) sebenarnya merupakan perkembangan dari metode rata-rata bergerak (moving average) sederhana.

Jika terdapat data dari t pengamatan maka nilai ramalan pada waktu $\mathrm{t}+1$ adalah:

$$
\begin{gathered}
S_{t+1}=\frac{X_{1}+X_{2}+\cdots+X_{t}}{t}=\frac{1}{t} \sum_{i=1}^{t} X_{i} \ldots(4) \\
S_{t+2}=X_{t+1}+\frac{1}{t}\left(X_{t+1}-X_{t}\right) \ldots(5)
\end{gathered}
$$

Sehingga metode pemulusan eksponensial untuk $\mathrm{N}$ pengamatan dapat dituliskan sebagai berikut:

$$
S_{t+1}=S_{t}+\left[\frac{X_{t}}{N}-\frac{X_{t-N}}{N}\right]
$$

Bila nilai observasi $X_{t-N}$ tidak tersedia maka harus diganti dengan nilai pendekatannya (aproksimasi). Dan salah satu pengganti yang mungkin adalah nilai ramalan periode $t$, yaitu $S_{t}$ sehingga diperoleh persamaan:

$$
\begin{gathered}
S_{t+1}=S_{t}+\left[\frac{X_{t}}{N}-\frac{S_{t}}{N}\right], \text { atau } \\
S_{t+1}=\left(\frac{1}{N}\right) X_{t}+\left(1-\frac{1}{N}\right) S_{t} .
\end{gathered}
$$

Karena $\mathrm{N}$ merupakan bilangan positif maka nilai $\frac{1}{N}$ akan menjadi suatu konstanta yang nilainya berkisar antara 0 sampai 1 . Jika nilai $\frac{1}{N}$ diganti dengan "alpha", maka persamaan diatas menjadi:

dimana,

$$
S_{t+1}=\alpha X_{t}+(1-\alpha) S_{t} \ldots . .(8)
$$

$S_{t+1}=$ nilai peramalan ke $\mathrm{t}+1$

$X_{t}=$ data aktual ke $\mathrm{t}$

$\alpha=$ parameter dengan nilai antara 0 sampai 1

$S_{t}=$ nilai peramalan ke $\mathrm{t}$ 


\section{Metode Penghalusan Eksponensial Orde Dua (Double Exponential Smoothing)}

Metode ini merupakan model linier yang dikemukakan oleh Brown. Model ini sesuai jika data yang dimaksud menunjukkan sifat trend, persamaan yang dipakai dalam implementasi pemulusan eksponensial ganda adalah: $F_{t+m}=a_{t}+b_{t} m$....(13)

Dengan $m$ merupakan jumlah periode ke muka yang diramalkan. (Makridakis et al.,1993).

\section{METODOLOGI PENELITIAN}

\section{Waktu dan Tempat Penelitian}

Penelitian ini dilakukan pada Bulan April-Mei 2013 di Fakultas Matematika dan Ilmu Pengetahuan Alam Universitas Samratulangi Manado (FMIPA UNSRAT).

\section{Variabel dan Cara Pengambilan Data}

Variabel penelitian ini adalah data pergerakan inflasi Kota Palu yang merupakan data bulanan dari Januari 2000 sampai dengan April 2013.

\section{Analisis Data}

1. Plot data

2. Penentuan model

3. Membuat dan mengembangkan model

4. Peramalan pada periode selanjutnya

\section{HASIL DAN PEMBAHASAN}

\section{Gambaran Pergerakan Inflasi}

Inflasi yang terjadi merupakan salah satu indikator pergerakan perekonomian disuatu kota. Inflasi ini memberikan informasi tentang pergerakan harga-harga barang dan jasa dalam suatu masyarakat. Pergerakan ini membuat harga-harga barang menjadi naik dan sering kali mengalami penurunan harga, namun jika pergerakannya stabil maka harga barang dan jasa tidak akan mengalami perubahan.
Tabel 1. Inflasi Kota Palu Menurut Kelompok Pengeluaran 1 Tahun Terakhir (Mei 2012 - April 2013).

\begin{tabular}{|l|c|c|c|c|c|c|c|}
\hline Bulan & BM & MI & P & S & K & PRO & TKJ \\
\hline Mei & $-0,31$ & 0,66 & $-0,15$ & 0.02 & 0,01 & 0 & 0,38 \\
\hline Juni & 2,77 & 0,34 & $-0,08$ & $-0,29$ & 3,45 & 1,09 & 0,21 \\
\hline Juli & 7,37 & 0,49 & 0,35 & 0,73 & 0,65 & 0,87 & $-1,63$ \\
\hline Agustus & 1,68 & 0,41 & 0,21 & 0,03 & 0,01 & 0,07 & 0,38 \\
\hline September & $-8,59$ & 1,41 & $-0,04$ & 0,97 & 0 & 0 & $-0,08$ \\
\hline Oktober & $-0,43$ & 0,04 & 0,01 & 0,02 & 0,05 & 0 & $-0,01$ \\
\hline November & $-0,45$ & $-0,003$ & 0,08 & $-0,03$ & 0,01 & 0,01 & $-0,14$ \\
\hline Desember & 5,77 & 0,74 & 0 & $-1,09$ & $-0,40$ & $-0,06$ & 1,19 \\
\hline Januari & 0,53 & 0,02 & 0,02 & $-0,03$ & 0 & 0 & $-0,36$ \\
\hline Februari & 0,17 & 0,01 & 0,46 & $-0,03$ & 0 & 0 & $-0,05$ \\
\hline Maret & $-1,11$ & 0,02 & 0,06 & $-0,43$ & 0,47 & 0 & 1,12 \\
\hline April & $-0,959$ & $-0,002$ & $-0,005$ & $-0,002$ & 0 & $-0,004$ & $-0,026$ \\
\hline
\end{tabular}

Sumber: Badan Pusat Statistika (BPS) Palu keterangan :

$\mathrm{BM}=$ Bahan Makanan; MJ = Makanan Jadi; $\mathrm{P}=$ Perumahan; $\mathrm{S}=$ Sandang; $\mathrm{K}=$ Kesehatan; PRK=Pendidikan, Rekreasi dan Olahraga TKJ=Transportasi, Komunikasi, dan Jasa

\section{Pengolahan Data \\ Plot Data}

Data pergerakan inflasi di Kota Palu dari Januari 2000 hingga April 2013 sebanyak 160 data dan digambarkan melalui plot time series pada gambar 1. Dengan melihat gambar 1, dapat dilihat bahwa data ini bersifat stasioner. Penyimpangan yang ada hanya terjadi pada bulan Juli tahun 2001 yaitu mengalami kenaikan sebesar 6,62 persen dan pada bulan September tahun 2000 mengalami penurunan atau terjadi deflasi sebesar $-3,25$ persen. Nilai terendah pergerakan inflasi mempunyai satuan negatif, yang artinya terjadi deflasi pada tahun 2000 hingga April 2013, deflasi ini terjadi sebanyak 45 bulan pengamatan.

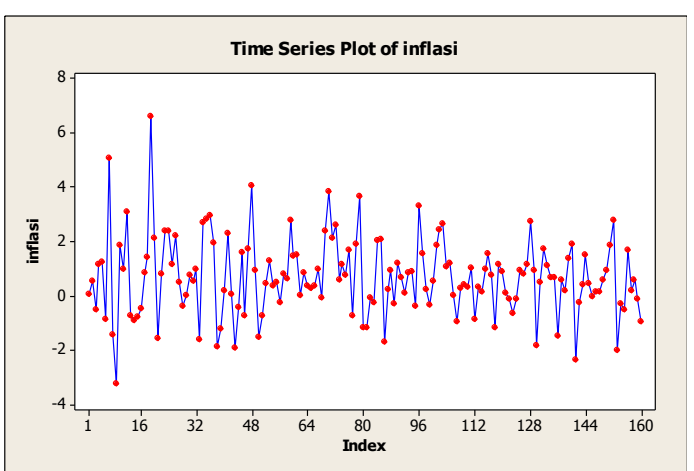

Gambar 1. Plot Data Pergerakan Inflasi di Kota Palu 


\section{Penentuan Model}

Dari hasil plot data diatas, dapat dilihat bahwa data pergerakan inflasi Kota Palu sejak januari 2000 hingga april 2013 bersifat stasioner. Dikatakan stasioner karena fluktuasi data beredar disekitar nilai rata-rata dan varians yang konstan serta tidak bergantung pada waktu. Oleh karena itu dapat ditentukan bahwa penelitian ini menggunakan metode single moving average dari moving average dan single eksponential smoothing dari eksponential smoothing.

\section{Karakteristik Data Pergerakan Inflasi Kota Palu}

Inflasi pada penelitian ini adalah data inflasi yang dikeluarkan oleh Badan Pusat Statistik Sulawesi Tengah (BPS SULTENG). Data bulanan pergerakan inflasi yang digunakan berjumlah 160. Data tersebut dibagi menjadi dua bagian yaitu periode pembuatan dan pengembangan (in-sample) dan periode peramalan (out-sample). Pembagian data tersebut dapat dilihat pada tabel 2.

Tabel 2. Pembagian Data

\begin{tabular}{|c|c|c|}
\hline No & Periode & Jumlah Data \\
\hline 1 & In-sample & 148 \\
\hline 2 & Out-sample & 12 \\
\hline \multicolumn{2}{|c|}{ Jumlah } & 160 \\
\hline
\end{tabular}

Rata-rata data pergerakan inflasi Kota Palu dari periode Januari 2000 sampai April 2013 sebesar 0,6873, sedangkan nilai tenganya sebesar 0,1123 . Nilai tertinggi dari periode data tersebut adalah 6,62 sedangkan nilai terendah adalah $-3,25$.

Tabel 3. Deskriptif Penelitian

\begin{tabular}{|c|c|}
\hline Mean & 0,6873 \\
\hline Median & 0,1123 \\
\hline Maximum & 6,62 \\
\hline Minimum & $-3,25$ \\
\hline Std.Dev & 1,4210 \\
\hline
\end{tabular}

\section{Pemeriksaan Metode Peramalan}

Metode peramalan single moving average, yaitu peramalan dengan dasar data bulan sebelumnya, untuk data in-sample peramalan terbaik yaitu pada single moving average 6 bulanan pada nilai MAPE (Mean Absolute Percentage Error) sebesar 310,546 dan single moving average 12 bulanan pada MAD (Mean Absolute Deviation) sebesar 1,050 serta MSD (Mean Squared Deviation) sebesar 1,941. sedangkan pada peramalan out-sample peramalan single moving average 12 bulanan tidak memberikan nilai. sehingga single moving average 6 bulanan merupakan metode yang terbaik karena nilai MAPE, MAD dan MSD mempunyai nilai terkecil dari metode peramalan single moving average 3 bulanan.

Tabel 4. Pemeriksaan Data In-sample dengan Single Moving Average

\begin{tabular}{|c|c|c|c|}
\hline \multirow{2}{*}{ Model } & \multicolumn{3}{|c|}{ In-sample } \\
\cline { 2 - 4 } & MAPE & MAD & MSD \\
\hline $\begin{array}{c}\text { Single moving average } \\
3 \text { bulanan }\end{array}$ & 312,845 & 1,329 & 3,062 \\
\hline $\begin{array}{c}\text { Single moving average } \\
6 \text { bulanan }\end{array}$ & 310,546 & 1,146 & 2,432 \\
\hline $\begin{array}{c}\text { Single moving average } \\
12 \text { bulanan }\end{array}$ & 315,859 & $\mathbf{1 , 0 5 0}$ & $\mathbf{1 , 9 4 1}$ \\
\hline
\end{tabular}

Tabel 5. Pemeriksaan Data Out-sample dengan Single Moving Average

\begin{tabular}{|c|c|c|c|}
\hline \multirow{2}{*}{ Model } & \multicolumn{3}{|c|}{ Out-sample } \\
\cline { 2 - 4 } & MAPE & MAD & MSD \\
\hline $\begin{array}{c}\text { Single moving average } \\
3 \text { bulanan }\end{array}$ & 229,047 & 1,376 & 3,204 \\
\hline $\begin{array}{c}\text { Single moving average } \\
\text { 6 bulanan }\end{array}$ & $\mathbf{1 2 2 , 9 7 6}$ & $\mathbf{0 , 7 2 0}$ & $\mathbf{0 , 7 6 2}$ \\
\hline
\end{tabular}

Tabel 6. Pemeriksaan Data In-sample dengan Single Eksponential Smoothing

\begin{tabular}{|c|c|c|c|}
\hline \multirow{2}{*}{ Model } & \multicolumn{3}{|c|}{ In-sample } \\
\cline { 2 - 4 } & MAPE & MAD & MSD \\
\hline $\begin{array}{c}\text { Single eksponential smoothing } \\
\text { alpha 0,1 }\end{array}$ & 269,407 & $\mathbf{1 , 0 8 7}$ & $\mathbf{2 , 1 7 4}$ \\
\hline $\begin{array}{c}\text { Single eksponential smoothing } \\
\text { alpha 0,5 }\end{array}$ & $\mathbf{2 5 8 , 9 3 8}$ & 1,217 & 2,713 \\
\hline $\begin{array}{c}\text { Single eksponential smoothing } \\
\text { alpha 0,9 }\end{array}$ & 295,344 & 1,343 & 3,301 \\
\hline
\end{tabular}


Tabel 7. Pemeriksaan Data Out-sample dengan Single Eksponential Smoothing

\begin{tabular}{|c|c|c|c|}
\hline \multirow{2}{*}{ Model } & \multicolumn{3}{|c|}{ out-sample } \\
\cline { 2 - 4 } & MAPE & MAD & MSD \\
\hline $\begin{array}{c}\text { Single eksponential smoothing } \\
\text { alpha 0,1 }\end{array}$ & 166,923 & 1,035 & 1,746 \\
\hline $\begin{array}{c}\text { Single eksponential smoothing } \\
\text { alpha 0,5 }\end{array}$ & 140,895 & 1,011 & 2,191 \\
\hline $\begin{array}{c}\text { Single eksponential smoothing } \\
\text { alpha 0,9 }\end{array}$ & 203,097 & 1,144 & 2,800 \\
\hline
\end{tabular}

Dari data diatas, dapat dilihat bahwa single eksponential smooting memberikan nilai yang lebih baik dari pada single moving average. Namun pada single eksponential smooting kita belum dapat memastikan metode peramalan dengan alpha 0,1 atau 0,5 yang akan menjadi metode peramalan pergerakan data inflasi kota palu, oleh karena itu kita membuat grafik dugaan untuk memilih metode peramalan yang terbaik.

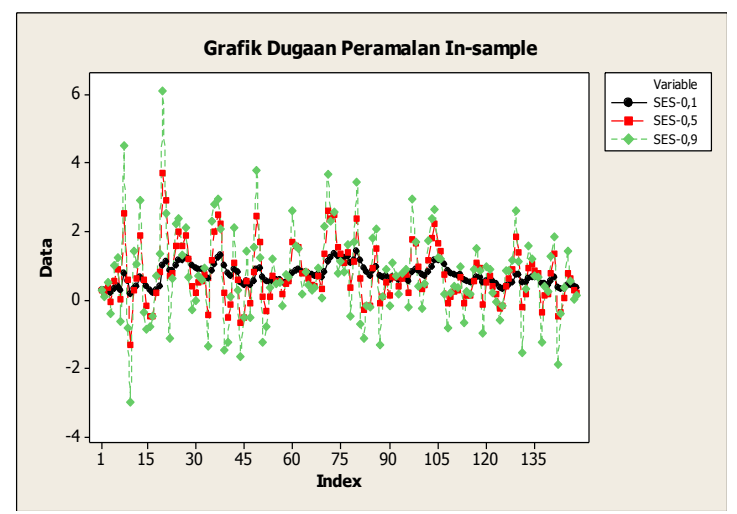

Gambar 2. Grafik Dugaan Peramalan Single Eksponential Smoothing pada In-sample

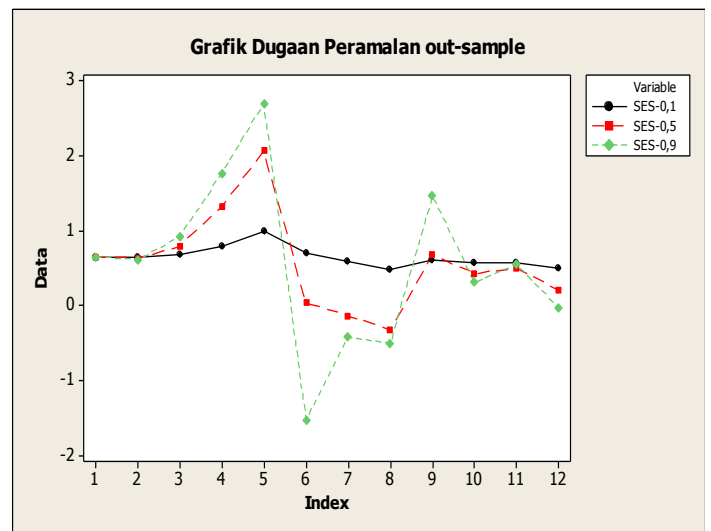

Gambar 3. Grafik Dugaan Peramalan Single Eksponential Smoothing pada Out-sample
Dari gambar grafik diatas dapat dilihat bahwa single eksponential smoothing dengan alpha 0,1 merupakan metode peramalan terbaik pada data in-sample dan out-sample.

\section{Peramalan Pergerakan Inflasi di Kota Palu pada Periode Selanjutnya}

Metode yang sesuai untuk peramalan pada pergerakan inflasi di Kota Palu adalah dengan metode single exponential smoothing dengan alpha 0.1 karena berdasarkan perhitungan error memiliki error forecast yang lebih baik dibanding dengan metode peramalan yang lain, baik dari in-sample maupun pada out-sample.

Berikut adalah perhitungan peramalan pergerakan inflasi pada tahun 2013 (Januari-Mei) di Kota Palu.

$\begin{aligned} \text { Forecast Januari } 2013 \quad: \quad & =(0,1 \times 1,69)+(1-0,1) 0,3410 \\ & =0,169+0,3069 \\ & =0,4759 \\ \text { Forecast Februari 2013 : } \quad & =(0,1 \times 0,18)+(1-0,1) 0,4759 \\ & =0,018+0,4283 \\ & =0,4463 \\ \text { Forecast Maret 2013 : } \quad & =(0,1 \times 0,58)+(1-0,1) 0,4463 \\ & =0,058+0,4017 \\ \text { Forecast April 2013 } \quad: \quad & =0,4597 \\ & =(0,1 \times(-0,10))+(1-0,1) 0,4597 \\ \text { Forecast Mei } 2013 & =-0,010+0,4137 \\ & =0,4037 \\ & =(0,1 \times(-0,95))+(1-0,1) 0,4037 \\ & =-0,095+0,3633 \\ & =0,2683\end{aligned}$

Tabel 8. Peramalan Pergerakan Inflasi pada Tahun 2011 (Januari-Mei) di Kota Manado

\begin{tabular}{|l|l|l|l|l|}
\hline Bulan & I & Inflasi & FITS! & RESII \\
\hline 1 & 157 & 0.18 & 0.47595 & -0.29595 \\
\hline 2 & 158 & 0.58 & 0.44636 & 0.13364 \\
\hline 3 & 159 & -0.10 & 0.45972 & -0.55972 \\
\hline 4 & 160 & -0.95 & 0.40375 & -1.35375 \\
\hline 5 & 161 & & 0.26837 & \\
\hline
\end{tabular}

Dari tabel 8 dapat dilihat bahwa pergerakan nilai inflasi Kota Palu mengalami kestabilan yang baik. Perubahannya tidak begitu besar, pada bulan Januari 2013, dimana diramalkan pergerakan inflasi sebesar 0,4759 persen, mengalami penurunan pada bulan Februari yaitu 0,4463 persen. Setelah itu pada bulan Maret diramalkan inflasi 
mengalami kenaikan sebesar 0,4597 persen. Kemudian mengalami penurunan lagi pada bulan April sebesar 0,4073 persen.

Pada bulan Mei 2013 diperoleh nilai peramalan pergerakan inflasi di Kota Palu sebesar 0,2683 persen, artinya pergerakan inflasinya pengalami penurunan juga dari bulan April.

\section{KESIMPULAN}

Berdasarkan analisis data yang telah dilakukan dapat disimpulkan bahwa peramalan pergerakan inflasi di Kota Palu pada Bulan Mei 2013 dengan menggunakan metode single eksponential smoothing dengan alpha 0,1 adalah sebesar 0,2683 persen, yang berarti pergerakan inflasi di Kota Palu kembali mengalami penurunan atau mengalami deflasi.

\section{DAFTAR PUSTAKA}

Badan Pusat Statistika Indonesia, 2013. http://www.bps.go.id. Ekonomi dan perdagangan. [6 mei 2013]

Handoko, T. Hani. 1984. Dasar-dasar Manajemen Produksi dan Operasi. Yogyakarta: BPFE UGM Yogyakarta.

Makridakis, S. 1992. Analisis Runtun Waktu. Karunika. Jakarta

Nanga, M. 2005. Makroekonomi: Teori, Masalah dan Kebijakan. Edisi Kedua. Jakarta: PT. Raja Grafika Persada.

Rahardja, P. 1997. Uang dan Perbankan. Jakarta: Rineka Cipta.

Raharja, A., el al. 2010. Penerapan Metode Exponential Smoothing untuk Peramalan Penggunaan Waktu Telepon Di PT. Telkomsel DIVRE3 Surabaya. SISFO Jurnal Sistem Informasi.

Subagyo, P. 1986. Forecasting Konsep dan Aplikasi. BPFE UGM. Yogyakarta. 